\title{
Building Integrating Phase Change Materials: A Dynamic Hygrothermal Simulation Model for System Analysis
}

\author{
Cesare Forzano*1, Paolo Baggio $^{2}$, Annamaria Buonomano ${ }^{3}$, Adolfo Palombo 4 \\ ${ }^{1}$ Free University of Bozen-Bolzano, Piazza Università 1, 39100 Bozen, Italy \\ e-mail: cesare.forzano@natec.unibz.it \\ ${ }^{2}$ Department of Civil, Environmental and Mechanical Engineering, University of Trento, Via Calepina \\ 14, 38122 Trento, Italy \\ e-mail: paolo.baggio@unitn.it \\ ${ }^{3}$ Department of Industrial Engineering, University of Naples Federico II, P. le Tecchio 80, \\ 80123 Naples, Italy \\ Department of Building, Civil, and Environmental Engineering, Concordia University, \\ 1455 De Maisonneuve Blvd. W., Montreal, Quebec H3G 1M8, Canada \\ e-mail: annamaria.buonomano@concordia.ca \\ ${ }^{4}$ Department of Industrial Engineering, University of Naples Federico II, P. le Tecchio 80, \\ 80123 Naples, Italy \\ e-mail: adolfo.palombo@unina.it
}

Cite as: Forzano, C., Baggio, P., Buonomano, A., Palombo, A., Building Integrating Phase Change Materials: A Dynamic Hygrothermal Simulation Model for System Analysis, J. sustain. dev. energy water environ. syst., 7(2), pp 325-342, 2019, DOI: https://doi.org/10.13044/j.sdewes.d6.0255

\begin{abstract}
Phase change materials are considered a very promising technology to reduce energy consumption for space heating and cooling purposes in buildings. In this framework, this paper presents a comprehensive energy performance analysis of building envelopes integrating phase change materials to provide suitable selection and design criteria of such technology. To this aim, an in-house dynamic simulation model implemented in a computer code, and validated by means of experimental data, has been used. The performance of phase change materials embedded in building enclosures and their optimal configuration (i.e., positions with respect to the construction layers) are evaluated. The results obtained by applying the code to suitable case studies (several climate zones and buildings are investigated) return that the energy saving percentage potentials per cubic meter of phase change materials range from $1.9 \% / \mathrm{m}^{3}$ to $18.8 \% / \mathrm{m}^{3}$. Finally, interesting design criteria for their adoption in buildings are provided.
\end{abstract}

\section{KEYWORDS}

Phase change materials, Dynamic energy performance analysis, Innovative building envelopes, Parametric analysis, Hygrothermal comfort, Heating and cooling energy.

\section{INTRODUCTION}

The building sector accounts for about 30-40\% of the world primary energy consumption in Organisation for Economic Cooperation and Development (OECD) regions. The majority of energy needs in buildings is due to heating, cooling and ventilation needs, necessary to provides indoor thermal comfort to occupants [1]. As the

\footnotetext{
* Corresponding author
} 
world's primary energy consumption is expected to keep growing due to the increase of world population (especially in developing countries), with rising standards of living [1], in order to address climate change issues the reduction of the energy consumption in buildings have become crucial. To this aim, the efficient design of new buildings and, particularly, the efficient renovation of the existing building stock are crucial toward the reduction of energy consumptions and greenhouse gas emissions [2].

In order to enhance the energy performance of new or retrofitted buildings, numerous energy efficiency measures and technologies, to be implemented into the building envelope exist, have been developed or set-up. They can be split into energy production systems, also based on renewables energies [3], and measures connected to the building thermophysical behaviour. Among building measures, those aiming at increasing the thermal mass of the building envelope, by decreasing and shifting the peak indoor air temperature, are a key factor for the decrease of heating and cooling requirements and peak loads and the enhancement of the occupants' comfort [4]. In order to achieve such a goal, different Thermal Energy Storage (TES) solutions based on sensible or latent heat storage can be adopted [5]. Nowadays, the main trend is to develop high rise buildings which, in turn, requires low weight construction materials. As a consequence, a reduced capability to exploit sensible heat storage is detected [6]. In this framework, Phase Change Materials (PCM's) could be a smart way to ensure indoor comfort conditions and to reduce building energy consumption by exploiting Latent Heat Thermal Energy Storage (LETES), being characterized by a high energy storage density [7, 8]. PCM's are in fact are able to absorb and release a high amount of latent heat during the phase transition, occurring in a narrow temperature range. Then, by incorporating a PCM's into building envelopes it is possible to increase its thermal inertia avoiding the use of massive construction materials (i.e., the heat capacity of PCM's is an order of magnitude higher than traditional building materials) [4]. Thus, they can function as additional thermal mass, improving the adaptability of the building envelope to changing external or internal conditions. Therefore, PCM's have been successfully incorporated into building envelopes, as reported in several case studies analyses such as in Lei et al. [9]. The energy savings potential of PCM's integrated into the building envelope ranges from 5-25\% of the annual cooling and heating requirements as a function of the weather and building use [4].

The increasing interest in PCM's adoption for building applications can be also proven by the presence of several review papers in literature on this topic. As an example, a number of works concerning the use of PCM's in building focus on the materials [10]:

- Thermophysical properties;

- Stability over time;

- Encapsulation typology;

- Behaviour in case of fire, etc.

Researchers underline the necessity of further researches about PCM's adoption in building in order to better understand their behaviour and the related economic convenience. In Souayfane et al. [11], the increasing importance of PCM's in the building sector is analysed by focusing on their impact on the achievable energy savings, also depending on the performance obtained by diverse melting and solidification curves. Another recent review work, presented in Kasaeian et al. [12], discusses the results of a comprehensive review, highlighting how the PCM's adoption in buildings could have positive effects on the heating, cooling, air-conditioning, and ventilation energy consumption. Results also show that the economic convenience of the system is higher for passive applications (PCM's integration into roofs, walls, glass and floor). Moreover, one of the main results of this review pointed out by the authors, is the necessity to develop dynamic simulation models in order to predict the PCM's performance in buildings and to assess their energy and economic convenience. One of the main issues 
with PCM's is, in fact, the selection of the suitable PCM for a certain application, as also underlined by Souayfane et al. [11]. In addition, although the building incorporation of PCM's has been extensively studied in Akeiber et al. [4], very few studies investigate their use for different weather zones, building usages and PCM's properties. As an example, in Fabiani and Pisello [13], an innovative PCM-doped concrete has been developed and tested. The results show that a more stable temperature is achieved during several tests by adding the PCM into the concrete. In another work, the energy performance of PCM's integrated into the building envelope, by means of a numerical approach, has been analysed by taking into account the tropical climate for only the cooling season [9]. Similarly, the investigation of the PCM performances in buildings, for the winter and summer seasons, has been carried out for the subtropical climate [14]. The influence of the weather on building integrated PCM performance has been analysed in Ascione et al. [15] by taking into account several climate zones, still focusing on just the cooling season. Another study underlining the importance of PCM's in order to reach the Net Zero Energy Building (NZEB) goal is reported in Stritih et al. [16]. Here by means of TRNSYS software the authors analyse the behaviour of a PCM layer integrated into the building wall. Specifically, here the authors underline the strong influence of the weather zone on PCM performance due to the fact that the PCM should be totally discharged in order to have the best benefits. As an example, low diurnal temperature variation implies high possibility of the incomplete melting - freezing cycle of PCM's with negative effects on the heat absorption process during the following cycle. Moreover, to ensure effective thermal storage of PCM's as passive cooling strategy, low night time temperatures are desirable, in this case, during the summer season, to enhance the PCM discharge (discarding the heat gains from the PCM's solidification) additional cooling and/or ventilation may be necessary. Such challenges are often relative to buildings located Mediterranean climate zone, as some of those investigated in this paper, along with cold and hot climate zones where PCM's are effective in a certain season only [17].

The available literature shows that most of the studies refer to heating or cooling dominated weather zones, focusing on seasonal performances, whereas different results are expected when building heating and cooling requirements are almost similar. This lack of knowledge is also pointed out in Xie et al. [18] where the authors analyse, by a numerical point of view, the performance of PCM integrated into the wall of a residential building.

In this framework, with the aim to assess the efficacy of integrating PCM's in building applications in different weather zones and for different building use, in this paper a comprehensive dynamic simulation analysis is presented. In particular, with the aim to find out suitable criteria to be easily adopted for the selection and the design of PCM's for building applications, the paper presents a numerical analysis, carried out by means of dynamic simulations. For this purpose, authors used an in-house developed computer code (written in MATlab and called DETECt 2.3) for the calculation of the whole building energy, economic and hygrothermal comfort performance. Such a code has already been modified to simulate building integrated PCM's [19, 20]. In this paper, two different composite PCM's, whose load curves are characterized by different peak melting and freezing temperatures, are implemented with the aim to evaluate how the thermophysical properties of PCM's modify the building heating and cooling needs. The whole building energy performance simulation code allows assessing the performance of PCM's by embedding them in building enclosures (e.g., roofs and walls or transparent elements) for any building envelope configuration (e.g., by placing PCM's in different positions with respect to the construction layers). In addition, to evaluate the advantages on the indoor comfort due to the use of PCM's, several comfort indexes (e.g. PPD, PMV, etc.) are calculated. 
Finally, a suitable case study based on a set of buildings of different design and operating features located in diverse climate zones is carried out. A comprehensive parametric study is performed in order to assess the effects of the above mentioned operating and design parameters on the system energy and economic performance and on the hygrothermal comfort of occupants. Interesting design criteria for the development and adoption of building embedded PCM's are provided. Moreover, an additional case study is carried out by taking into account residential and office buildings, six different weather zones and two composite PCM embedded in diverse building envelope components. The influence of the phase change temperature, location, and amount of PCM's on building envelope on the heating and cooling requirements is studied and discussed. Finally, at the authors' knowledge this paper contributes to the state-of-the-art by investigating the energy performance of building envelopes integrating PCM's for heating and cooling consumption and peak load reduction through numerical simulation.

\section{SIMULATION MODEL}

With the aim of assessing the energy performance analysis of building embedded PCM's, a purpose-developed simulation model has been conceived and then implemented in a previously developed simulation software called DETECt $2.3[19,21]$. This mathematical tool, implemented in MATlab environment, has been validated by means of the code to code and experimental procedures as reported in several previous works. Specifically, in Buonomano et al. [22], the authors validated the software by means of a code to code procedure and by following the BESTTEST procedure [23]. The potential of the code has been proven by investigating several case studies [24] such as NZEB buildings [25]. Lately, the software reliability has been further proven by an experimental validation procedure [26]. The software is able to dynamically analyse the building energy behaviour. The code was conceived to examine innovative technologies to be integrated into the building shield, as well as to find out optimal design and operating conditions, to be carried out by means of the embedded parametric analysis tool, toward the design of high energy efficient buildings, such as NZEB's.

The building model is based on a high order Resistive-Capacitive (RC) thermal network [27], by taking into account two main assumptions:

- The conductive heat transfer is supposed to be one-dimensional (also through the PCM layers);

- All materials are considered as isotropic.

In DETECt, each thermal zone is divided into $M$ building elements (wall, floor, roof, etc.), each of them is split in $N$ thin sub-layer of different thicknesses, returning a very high number of nodes simulating the mutual interaction between real building elements [27]. Note that such approach is particularly useful for analysing the thermal behaviour of PCM's [27]. An example of an RC thermal network of a generic $m$-th building element split in $N+2$ nodes is represented in Figure 1 (inside of building on the right, outside of building on the left). Here, several energy interactions can be detected:

- Transmission through opaque and transparent elements;

- Solar radiation absorbed by the exterior and the interior surfaces;

- Solar energy absorbed by and transmitted through fenestration;

- Internal long-wave radiation exchanges and solar radiation distribution within a thermal zone;

- Infiltration and natural ventilation;

- Heat gains due to equipment and occupants.

In order to solve the algebraic and differential equations describing the whole building thermal network, an implicit finite difference approach is used and an iterative method throughout the whole number of integration sample times is considered. With respect to 
the PCM modelling approach, a backward scheme is used [28]. In the following, a brief description of the building model is reported, whereas further details are reported in Buonomano [29].

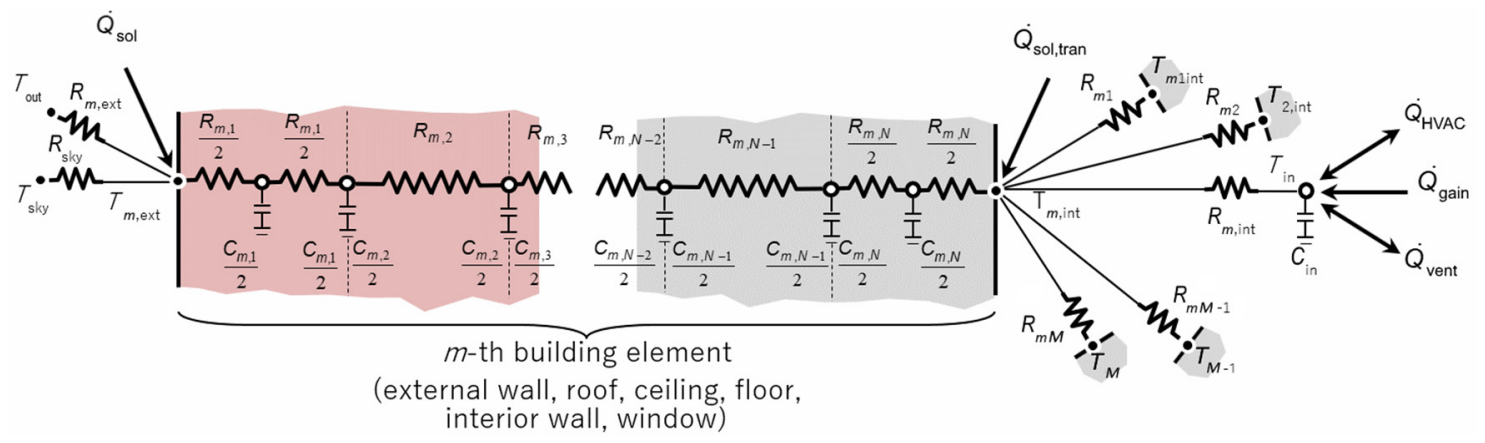

Figure 1. Schematics of the RC thermal network

In each time step and for each capacitive $n$-th node $(1 \leq n \leq N)$ of the $m$-th building element $(1 \leq m \leq M)$, the differential equation describing the heat transfer is:

$$
C_{m, n} \frac{d T_{m, n}}{d t}=\sum_{j=n-1}^{n+1} \frac{T_{m, j}-T_{m, n}}{R_{m, j}^{\mathrm{eq}}}+\dot{Q}_{m, n}
$$

where $C_{m, n}$ and $T_{m, n}$ are the thermal capacitance and the temperature of the $n$-th node, whereas $R_{m, j}^{\mathrm{eq}}$ is the thermal resistance coupling such node to the neighbor ones. $R_{m, j}^{\mathrm{eq}}$ is either a convective (external $R_{m, 0}^{\text {conv }}$ or internal $R_{m, N+1}^{\text {conv }}$ ) or a conductive $\left(R_{m, n}^{\text {cond }}\right)$ resistance, depending on the side layer of the considered node. For non-capacitive outer $(j=0)$ and inner $(j=N+1)$ surface nodes (i.e., $C_{m, n}$ is neglected), $R_{m, 0}^{\text {conv }}$ and $R_{m, N+1}^{\text {conv }}$ connect noncapacitive nodes to those linked to the outdoor air temperature $\left(T_{\text {out }}\right)$ and to the indoor air ( $\left.T_{\text {in }}\right)$ one. $\dot{Q}_{m, n}$ is a forcing function including the incident solar and the long-wave radiation exchange acting on outer and inner surfaces nodes, evaluated as described in Judkoff and Neymark [23].

The differential equation on the thermal network node of the indoor air, to be solved simultaneously with the system of eq. (1), is:

$$
C_{\text {in }} \frac{d T_{\text {in }}}{d t}=\sum_{m=1}^{M} \frac{T_{m, N}-T_{\text {in }}}{R_{m, N+1}^{\text {conv }}}+\frac{\left(T_{\text {out }}-T_{\text {in }}\right)}{R_{\mathrm{v}}}+\dot{Q}_{\mathrm{g}} \pm \dot{Q}_{\mathrm{HC}}^{\mathrm{s}}
$$

where $C_{\text {in }}$ and $T_{\text {in }}$ are the thermal capacitance and temperature of the zone indoor air, $R_{\mathrm{V}}$ is a convective thermal resistance related to air ventilation and infiltration, $\dot{Q}_{\mathrm{g}}$ is the sensible heat gains (due to occupants, lights and equipment), $\dot{Q}_{\mathrm{HC}}^{\mathrm{s}}$ is the sensible heat to be supplied to (or removed from) the thermal zone by an ideal heating and cooling system, aiming at maintaining the indoor air at the desired set point temperature [25].

\section{Phase Change Materials modelling}

The main novelty of the proposed simulation model concerns the modelling of the thermal behaviour of building integrated PCM, modelled as building envelope layers [19]. In DETECt, the effective heat capacity method is considered for modelling the PCM thermal behaviour [30]. The choice of such method, among those available in literature, 
is due to its simplification, being the PCM studied as a single-phase non-linear conduction problem (i.e., latent heat is considered as an increased form of sensible heat in the transition phase) [31]. Specifically, in order to take into account in eq. (1), the PCM phase change a thermal capacitance function of the PCM layer temperature is assumed [i.e. $C_{m, n}=C_{m, n}\left(T_{m, n}\right)$ ]. Note that the PCM specific heat and the thermal conductivity are assumed as constant in case of single phase (solid or liquid). Conversely, when PCM is undergoing phase change, its specific heat and thermal conductivity vary as a function of the temperature of the previous time step. The values of specific heat capacity and conductivity for several PCM typologies are available by adopting suitable experimental correlations obtained through laboratory tests or provided by manufacturers [32]. In DETECt, such correlations are exploited with the aim of studying several PCM's encapsulated in matrixes made by traditional building materials (gypsum, concrete, etc.).

The above mentioned effective PCM heat capacity fits a Gaussian shaped curve [31], where the maximum corresponds to the peak melting temperature [18], expressed as:

$$
C_{m, n_{\mathrm{PCM}}}\left(T_{m, n_{\mathrm{PCM}}}\right)=M_{m, n_{\mathrm{PCM}}} a \times e^{-\left(\frac{T-b}{c}\right)^{2}}
$$

where $M_{m, n_{\mathrm{PCM}}}$ is the mass of the PCM layer, $a$ is the maximum increment of the PCM specific heat due to the latent heat, $b$ is the average temperature of the phase change for melting and solidification and $c$ is the range of the phase change. Further details are available in Buonomano et al. [19] or Buonomano et al. [21].

Finally, it is worth noting that in DETECt both the melting and solidification curve are modelled, together with the hysteresis phenomenon, whereas very few mathematical models related to the PCM's take into account both curves. In most of the studies available in the literature carried out by means of commercial software or codes the hysteresis phenomenon has been neglected (only recently modelled [33]).

\section{Comfort indexes}

In order to analyse the hygrothermal comfort in each building thermal zone, DETECt 2.3 allows dynamically calculating the following comfort indexes:

- Predicted Mean Vote (PMV), representing the comfort perception of a large population of people exposed to a certain environment. By establishing a thermal stress based on steady-state heat transfer between the body and the environment, the thermal strain is ranked with a comfort vote. Further details about PMV are reported in [34];

- Predicted Percentage of Dissatisfied (PPD), representing the predicted percentage of dissatisfied people at each PMV. PPD varies as PMV ranges between -3 (very cold) to 3 (very hot), zero being the neutral conditions. Additional details about PPD are reported in d'Ambrosio Alfano et al. [35];

- Mean radiant temperature of the indoor building space $\left(T_{\mathrm{r}}\right)$. It is the uniform temperature of an ideal space in which the radiant heat transfer between occupants and internal surfaces is equal to the radiant heat transfer occurring in a real nonuniform space.

\section{CASE STUDY}

In order to show the potential of the simulation model and the effectiveness of PCM's integrated in the building envelope for energy savings and occupants' comfort, a suitable case study is carried out. To this aim, PCM's are integrated into interior and exterior walls of a sample building, alternatively used as commercial building, office and dwelling. The 
building is located in different weather zones characterized by very cold, cold, warm, hot and Mediterranean temperate climates, such as: Naples and Palermo (Italy), Almeria (Spain), Athens (Greece), Jerusalem (Israel), Montreal (Canada), and Denver (USA).

A sample $8.0 \times 6.0 \mathrm{~m}$ rectangular shaped lightweight building (with East-West oriented longitudinal axis), $3.0 \mathrm{~m}$ height, is modelled, as shown in Figure 2. The $U$-values of vertical walls, roof and windows are respectively $0.49,0.30$, and $1.70 \mathrm{~W} / \mathrm{m}^{2} \mathrm{~K}$. The Solar Heat Gain Coefficient (SHGC) of the window is set to 0.262.

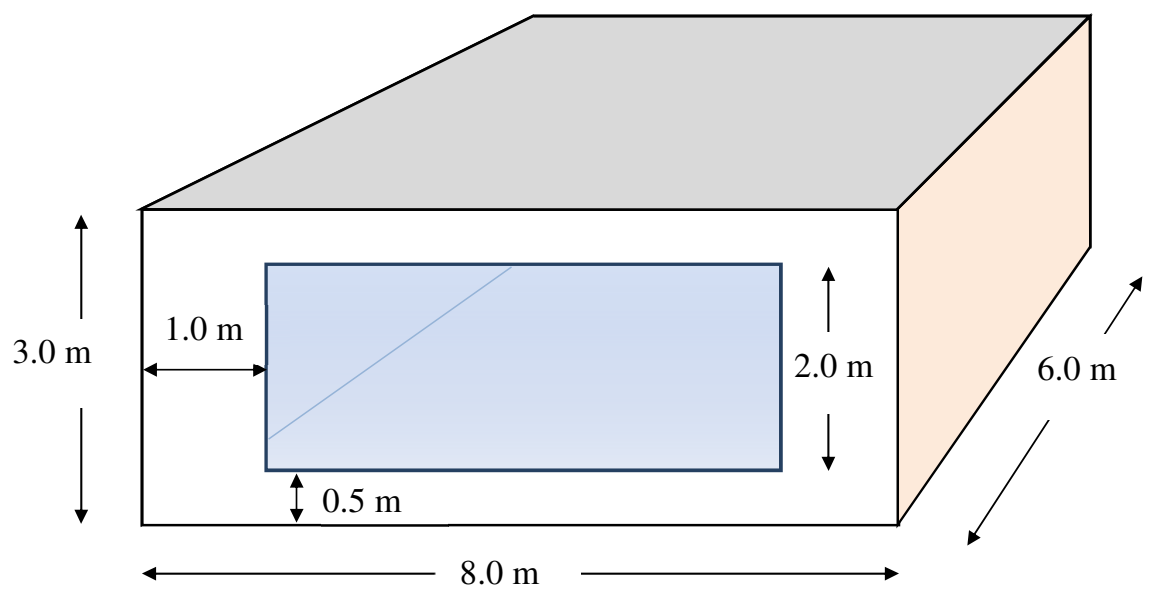

Figure 2. Sketch of the sample building

Occupancy indexes are 0.03 people $/ \mathrm{m}^{2}$ for the dwelling, 0.06 for the office, and 0.12 for the commercial building. The number of air changes for residential and nonresidential uses are 0.5 and $1.2 \mathrm{Vol} / \mathrm{h}$, respectively. In addition, a night free cooling ventilation is taken into account $(2.0 \mathrm{Vol} / \mathrm{h})$ for outdoor air temperatures lower than the indoor one. Dynamic simulations are performed on the yearly basis by using Meteonorm weather data files for the considered weather zones. The Heating, Ventilation and Air Conditioning (HVAC) system is modelled by an electric air-to-water chiller/heat pump (by taking into account variable performance, nominal heating and cooling $\mathrm{COP}=3.0$ and 2.5), necessary to prevent the indoor air temperature exceeding the thermal comfort range, between 20 and $26{ }^{\circ} \mathrm{C}$. The overall energy performance analysis is based on the system operation scheduled as in Table 1.

Table 1. Climatic zones, climatic indexes and system scheduling

\begin{tabular}{|c|c|c|c|c|c|c|}
\hline Weather zone & $\begin{array}{c}\text { Heating Degree } \\
\text { Days (HDD) } \\
\text { [Kelvin day ] }\end{array}$ & $\begin{array}{c}\text { Cooling Degree } \\
\text { Days (CDD) } \\
\text { [Kelvin day] }\end{array}$ & $\begin{array}{c}\text { Incident Solar } \\
\text { Radiation (ISR) } \\
{\left[\mathrm{kWh} / \mathrm{m}^{2} \mathrm{y}\right]}\end{array}$ & Use & $\begin{array}{l}\text { Heating months } \\
\text { [hours] }\end{array}$ & $\begin{array}{c}\text { Cooling months } \\
\text { [hours] }\end{array}$ \\
\hline Montreal & 4,567 & 297 & 1,350 & $\begin{array}{c}\text { Dwelling } \\
\text { Office } \\
\text { Commercial } \\
\end{array}$ & $\begin{array}{c}15 / 9-31 / 3 \\
(0-24) \\
(8-24) \\
(8-20) \\
\end{array}$ & $\begin{array}{c}1 / 6-15 / 9 \\
(11-18) \\
(8-24) \\
(8-20) \\
\end{array}$ \\
\hline Denver & 2,667 & 77 & 988 & $\begin{array}{c}\text { Dwelling } \\
\text { Office } \\
\text { Commercial } \\
\end{array}$ & $\begin{array}{c}15 / 9-31 / 3 \\
(0-24) \\
(8-24) \\
(8-20) \\
\end{array}$ & $\begin{array}{c}1 / 6-15 / 9 \\
(11-18) \\
(8-24) \\
(8-20) \\
\end{array}$ \\
\hline Jerusalem & 1,482 & 771 & 2,039 & $\begin{array}{c}\text { Dwelling } \\
\text { Office } \\
\text { Commercial } \\
\end{array}$ & $\begin{array}{c}15 / 11-31 / 3 \\
(7-10,14-21) \\
(8-24) \\
(8-20) \\
\end{array}$ & $\begin{array}{c}1 / 6-30 / 9 \\
(11-18) \\
(8-24) \\
(8-20) \\
\end{array}$ \\
\hline Naples & 1,479 & 499 & 1,470 & $\begin{array}{c}\text { Dwelling } \\
\text { Office } \\
\text { Commercial } \\
\end{array}$ & $\begin{array}{c}15 / 11-31 / 3 \\
(7-10,14-21) \\
(8-24) \\
(8-20) \\
\end{array}$ & $\begin{array}{c}1 / 6-30 / 9 \\
(11-18) \\
(8-24) \\
(8-20) \\
\end{array}$ \\
\hline Athens & 1,060 & 1,201 & 1,561 & $\begin{array}{c}\text { Dwelling } \\
\text { Office } \\
\text { Commercial } \\
\end{array}$ & $\begin{array}{c}15 / 11-31 / 3 \\
(7-10,14-21) \\
(8-24) \\
(8-20) \\
\end{array}$ & $\begin{array}{c}1 / 6-30 / 9 \\
(11-18) \\
(8-24) \\
(8-20) \\
\end{array}$ \\
\hline Palermo & 760 & 987 & 1,664 & $\begin{array}{c}\text { Dwelling } \\
\text { Office } \\
\text { Commercial } \\
\end{array}$ & $\begin{array}{c}1 / 12-31 / 3 \\
(7-10,14-21) \\
(8-24) \\
(8-20) \\
\end{array}$ & $\begin{array}{c}1 / 6-30 / 9 \\
(11-18) \\
(8-24) \\
(8-20) \\
\end{array}$ \\
\hline
\end{tabular}


Two different PCM's are analysed, their melting and solidification curves are shown in Figure 3. Here, the $c_{\mathrm{p}}$ curves of the first modelled PCM's, namely $\mathrm{PCM}_{\mathrm{a}}$, are obtained by experimental data provided by Kuznik et al. [36]. The melting and solidification curves of the second PCM, namely PCM $\mathrm{P}_{\mathrm{b}}$, are obtained by shifting the $c_{\mathrm{p}}$ of $\mathrm{PCM}_{\mathrm{a}}$ toward higher peak temperatures. The selected peak melting temperatures are 19 and $23{ }^{\circ} \mathrm{C}$ for $\mathrm{PCM}_{\mathrm{a}}$ and $\mathrm{PCM}_{\mathrm{b}}$, respectively. Simulation data are referred to composite material panels obtained by mixing gypsum with PCM paraffin microcapsules. In fact, the PCM's are a mixture of $40 \%$ ethylene-based polymer and $60 \%$ paraffin wax, with a density of $900 \mathrm{~kg} / \mathrm{m}^{3}$. The panels $(5.2 \mathrm{~mm}$ thick, $1,000 \mathrm{~mm}$ wide and $1,198 \mathrm{~mm}$ long) are encapsulated within $100 \mu \mathrm{m}$ aluminium layer on both sides. Note that the same amount of stored and released energy are selected and simulated for both the simulated materials, $\mathrm{PCM}_{\mathrm{a}}$ and $\mathrm{PCM}_{\mathrm{b}}$.

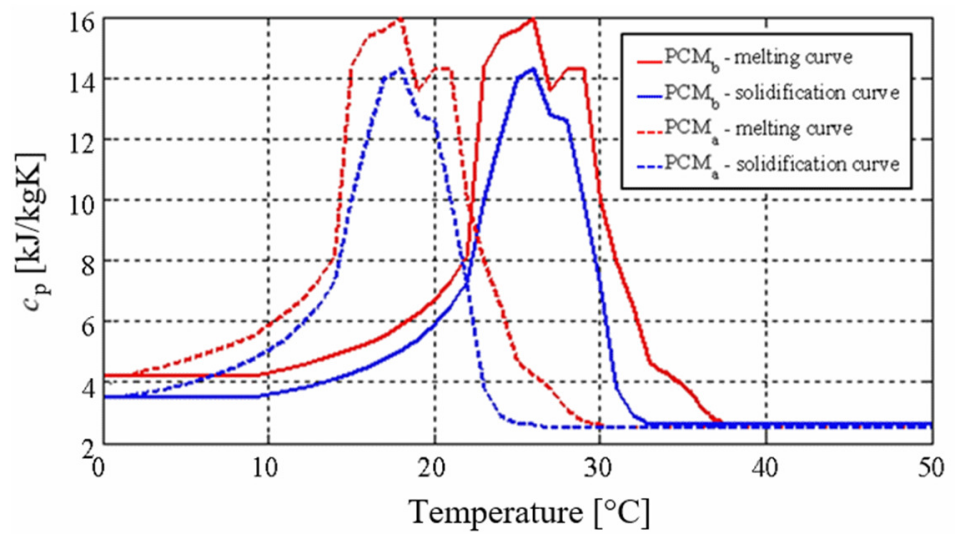

Figure 3. Trends of the specific heat of the two investigated composite PCM's

\section{RESULT AND DISCUSSION}

The building envelope integration of PCM layers influences both heating and cooling demands due to the charging and discharging cycle. Such phenomenon is mainly governed by the PCM melting temperature range and peak.

In order to show this thermal behaviour, a first discussion concerning the commercial building use, with HVAC running hours range from 08:00 to 20:00, is presented. Figure 4 shows the indoor air temperatures and sensible heating loads calculated for the weather zone of Denver in five sample winter days (March $11^{\text {th }}-16^{\text {th }}$ ), for the building envelope integrating $\mathrm{PCM}_{\mathrm{a}}$ in East, West walls and roof (internal position) and for the reference one (without PCM). The indoor air temperature for the reference case $\left(T_{\mathrm{in}, \mathrm{ref}}\right.$, blue line) is compared to the case with $\mathrm{PCM}_{\mathrm{a}}\left(T_{\mathrm{in}, \mathrm{PCM}}\right.$, orange line), by taking into account a daily heating schedule (09:00-17:00). $T_{\text {in,PCM }}$ is higher than $T_{\text {in,ref }}$ when the HVAC system is turned off, therefore, when the HVAC system is activated, the corresponding maximum sensible load ( $Q_{\text {heat,PCM}}$, orange line) is lower than that one of the reference case $\left(Q_{\text {heat,ref, blue line). }}\right.$

The integration of PCM (i.e., $\mathrm{PCM}_{\mathrm{a}}$ at the internal position), due to the consequent peak load reduction, implies the need of lower sized HVAC systems with respect to the reference case (no PCM). Nevertheless, during daily hours when the HVAC system is switched on (i.e., $T_{\mathrm{in}, \mathrm{PCM}}$ and $T_{\mathrm{in}, \mathrm{ref}}$ maintained at the winter set point indoor air temperature of $20{ }^{\circ} \mathrm{C}$ ), the required sensible load, $Q_{\text {heat,PCM, }}$, is higher than $Q_{\text {heat,ref, due to }}$ the higher thermal capacitance of the building envelope. In fact, during the whole winter season, an increase of the heating energy requirements (about $+18 \%$ ) is obtained by using PCM. Obviously, such heat, stored within the layers of PCM, is transferred to the indoor thermal zone in the late evening/night hours, when the HVAC system is switched off (i.e., commercial use of the building) and the building is not occupied, not exploiting most of 
the energy and comfort advantages of PCM's. This can be observed by analysing the comfort indexes profiles, $T_{\mathrm{r}}, \mathrm{PMV}$ and PPD, shown in Figure 5 and calculated for the same building envelopes and sample days of Figure 4. Here, it is possible to note that all such indexes improve when PCM's are used, but such improvement occurs during not occupied hours (grey areas), higher $T_{\mathrm{r}}$ and PMV (i.e. closer to 0), lower PPD.

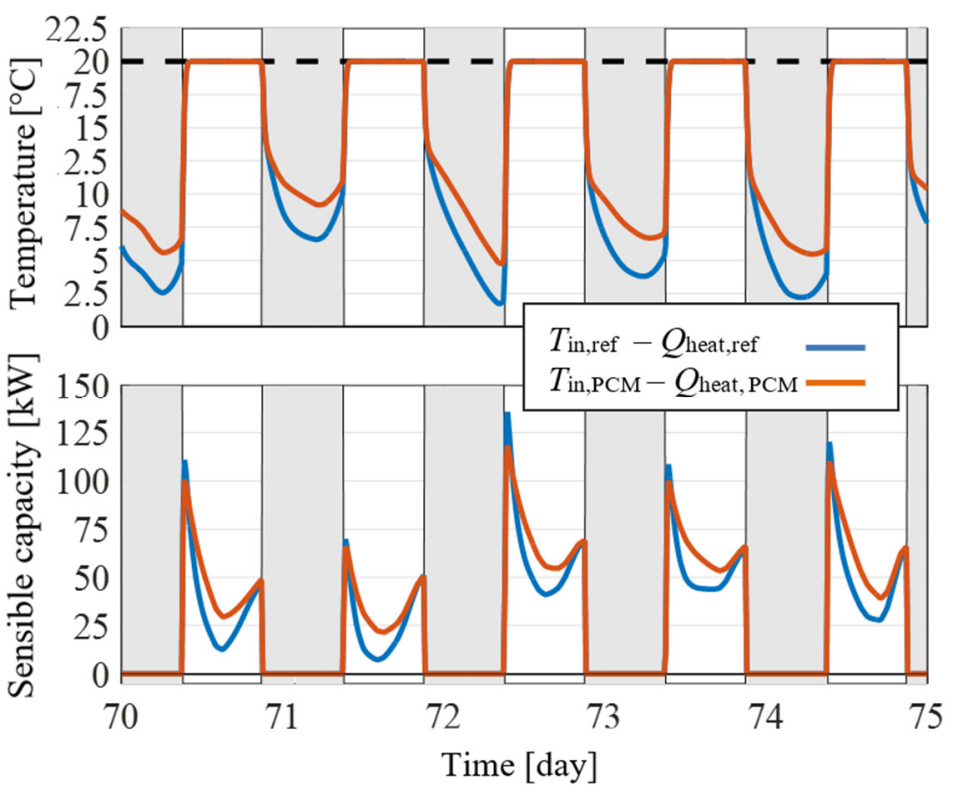

Figure 4. Indoor air temperature and sensible heating load - March $11^{\text {th }}-16^{\text {th }}$ Denver

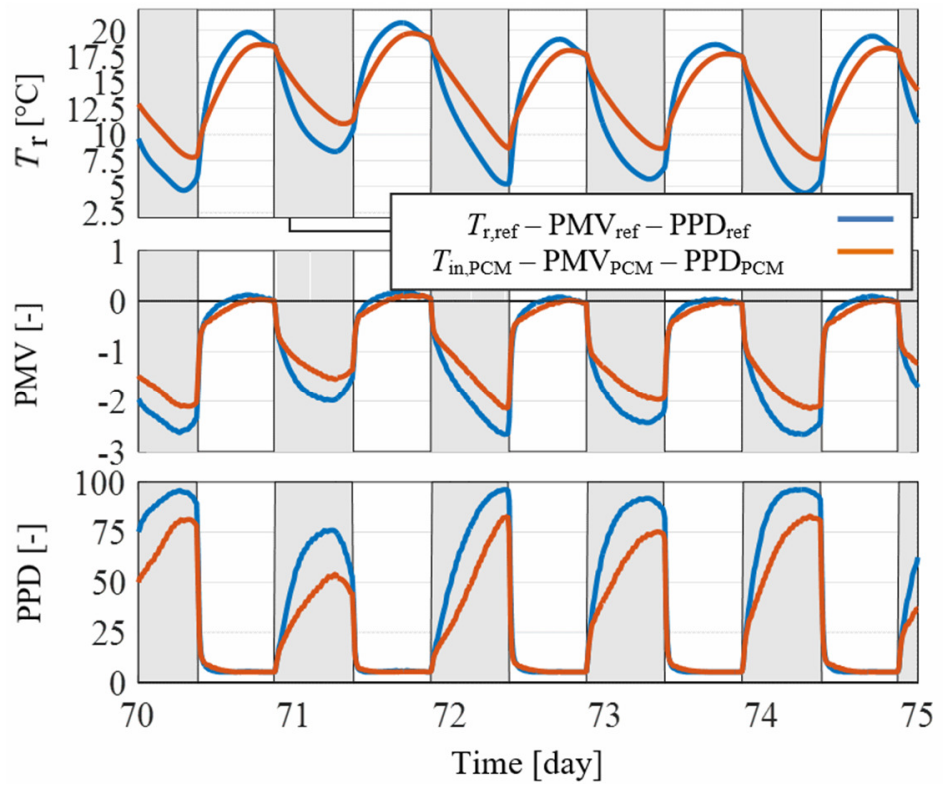

Figure 5. $T_{\mathrm{r}}, \mathrm{PMV}$ and PPD - March $11^{\text {th }}-16^{\text {th }}$ Denver

In case of a building with and without PCM's, the indoor air temperatures are shown and compared in Figure 6 for the same conditions and weather zone of Figure 4, by taking into account five summer sample days instead of winter days. This figure shows that during summer, the advantages due to the use of PCM's (e.g., reduced fluctuation of the indoor air temperature) occur during occupied daily hours, with a consequent reduction of cooling requirements and an increase of occupants' comfort. In fact, the increase of the thermal inertia, achieved by means of the PCM layers integrated into the building envelope, causes an attenuation of the indoor air temperature, resulting in reduced cooling 
loads. On a yearly basis, the cooling requirement decreases of about $40 \%$ with respect to the reference case.

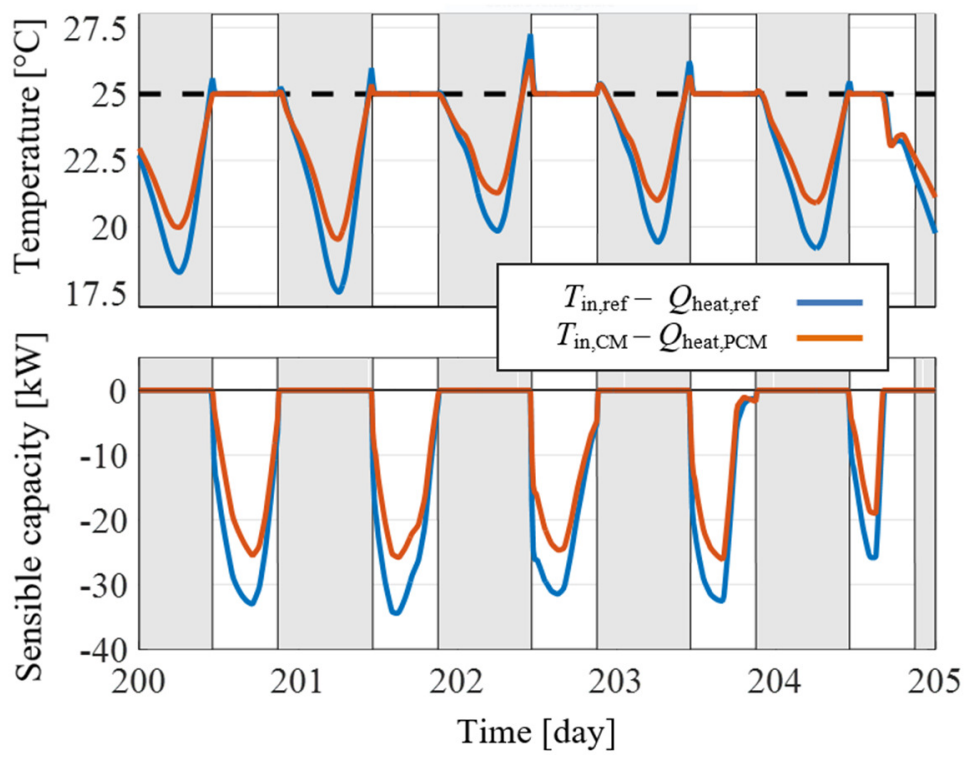

Figure 6. Indoor air temperature and sensible heating load - July $20^{\text {th }}-25^{\text {th }}$ Denver

Similarly, the profile of the comfort indexes calculated for the summer sample days, $T_{\mathrm{r}}$, PMV and PPD, reported in Figure 7, shows that the integration of PCM causes a higher $T_{\mathrm{r}, \mathrm{PCM}}$ with respect to $T_{\mathrm{r}, \mathrm{ref}}$ also during daily hours when the HVAC system is turned on and the building is occupied. The same considerations can be applied to the PMV which in case of PCM is closer to the neutral point, with a consequent increase of the PPD.

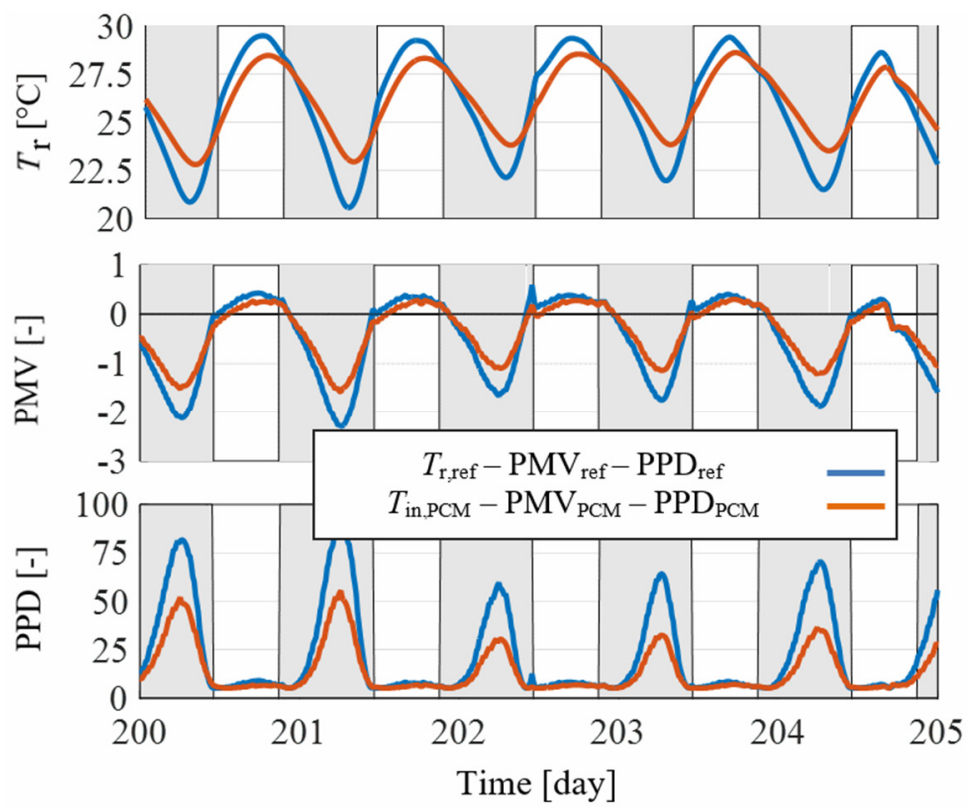

Figure 7. $T_{\mathrm{r}}$, PMV and PPD - July $20^{\text {th }}-25^{\text {th }}$ Denver

The effectiveness of the $\mathrm{PCM}_{\mathrm{a}}$ and $\mathrm{PCM}_{\mathrm{b}}$, which may be considered alternatively suitable for heating and cooling dominated zones, is also analysed. Note that the two PCM's, i.e., PCM $_{a}$ (considered as suitable for heating-dominated zones) and PCM (considered as suitable for cooling-dominated zones), store and release the same amount of energy. 
In the following, the overall energy simulation results, obtained for two building use, dwelling and office, are discussed. Note that the considered heating and cooling schedules are those reported in Table 1. For the weather zone of Denver and the office building, the obtained monthly results are reported in Figure 8, where, the PCM is integrated into East and West walls, as well as in the roof. In such figure, the electricity demand of the chiller/heat pump is reported as a function of the different investigated system layouts. For the office building use, the best configuration is obtained by integrating the PCM externally to the building envelope. The overall summer cooling energy savings are maximized by boosting the PCM charge/discharge effect through a night free cooling ventilation. In addition, during night hours the absence of internal heat gains allows the PCM to complete a charge/discharge cycle. It is also worth noting that the PCM also causes a lower heating demand during the colder winter months. In fact, the heat stored within the PCM layers (i.e. charging mode), when integrated into internal positions, is provided by HVAC system, thus an increase of the heating demand vs. the reference case (no PCM) is observed. Contrarily, when the PCM's is located externally to the building envelope, a heating saving, also in colder months, is observed. In this case, the heat stored within the PCM's is provided by solar radiation (as a function of the solar altitude and angle), and it is transmitted toward the outdoor and indoor environment, shifted in time. Thus, heating energy saving is achieved by exploiting the free solar heat stored by the PCM during winter sunny days.

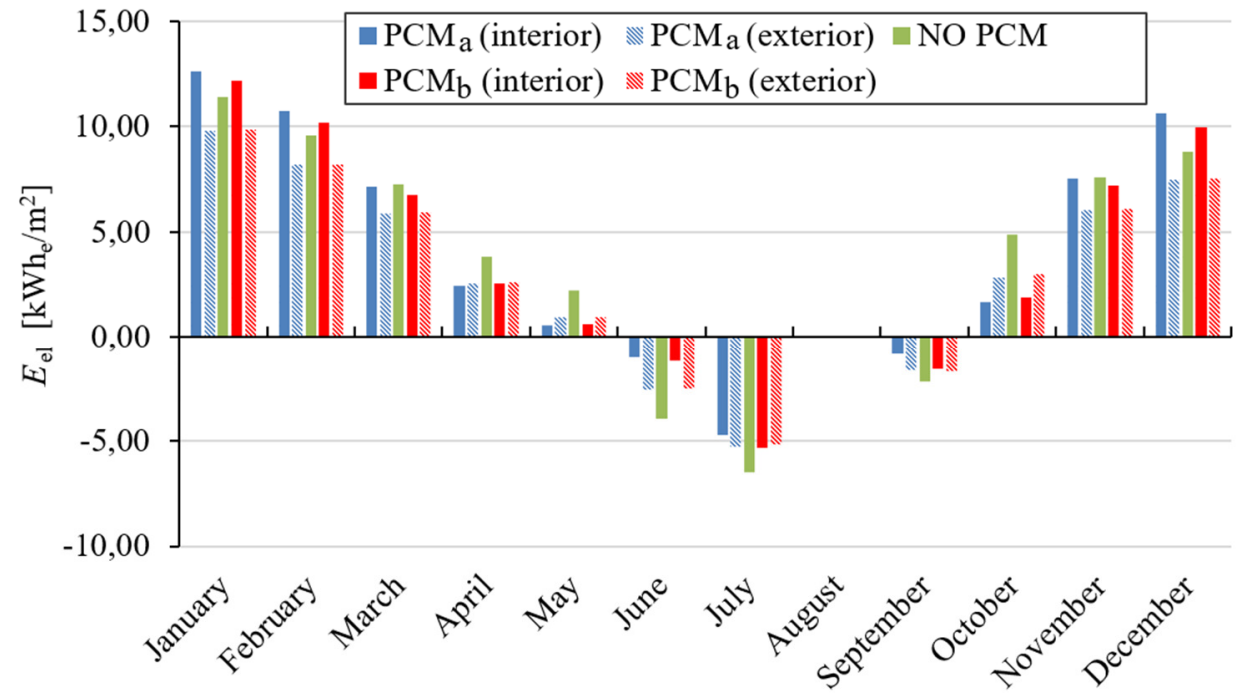

Figure 8. Office building in Denver: monthly results

It is worth noting that for the office use, a continuous HVAC system running from 08:00 to 24:00 is taken into account (differently from the commercial building use, discussed before, where running hours range from 08:00 to 20:00). The energy behaviours analysed by means of the monthly results reported in Figure 8, can be further discussed through Figure 9 and Figure 10. Here, the time histories of the office indoor air temperature $\left(T_{\mathrm{in}}\right)$, relative to the reference configuration (no PCM), and the two investigated PCM's (i.e. $\mathrm{PCM}_{\mathrm{a}}$ and $\mathrm{PCM}_{\mathrm{b}}$ ) for both the PCM layouts (i.e. considered in external and internal envelope positions), are shown for two winter (January $11^{\text {th }}$ and $12^{\text {th }}$ - Figure 9) and summer (July $6^{\text {th }}$ and $7^{\text {th }}$ - Figure 10) sample days. During the day-time, when the HVAC system is switched on, the required indoor air temperature set points $\left(20{ }^{\circ} \mathrm{C}\right.$ and $\left.26^{\circ} \mathrm{C}\right)$ are always reached, whereas in night-time the indoor air temperature is free to float. In winter, the minimum indoor air temperature decrease, obtained during the night time, occurs in case of the internal PCM positions (as expected due to the stored heat delivered toward the indoor zone during night-time). Nevertheless, such 
configurations require much more energy during the HVAC running time, as discussed before.

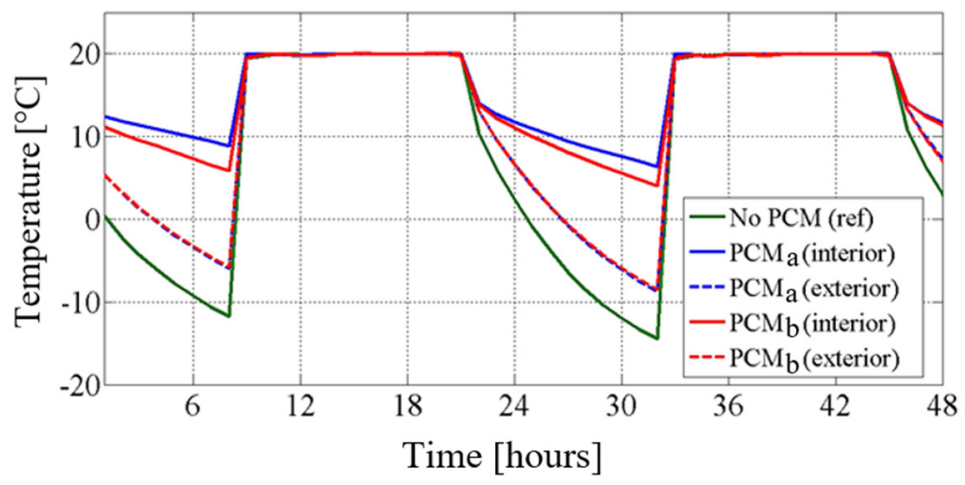

Figure 9. Indoor air temperatures for different building envelope configurations (office building in Denver, January $11^{\text {th }}$ and $12^{\text {th }}$ )

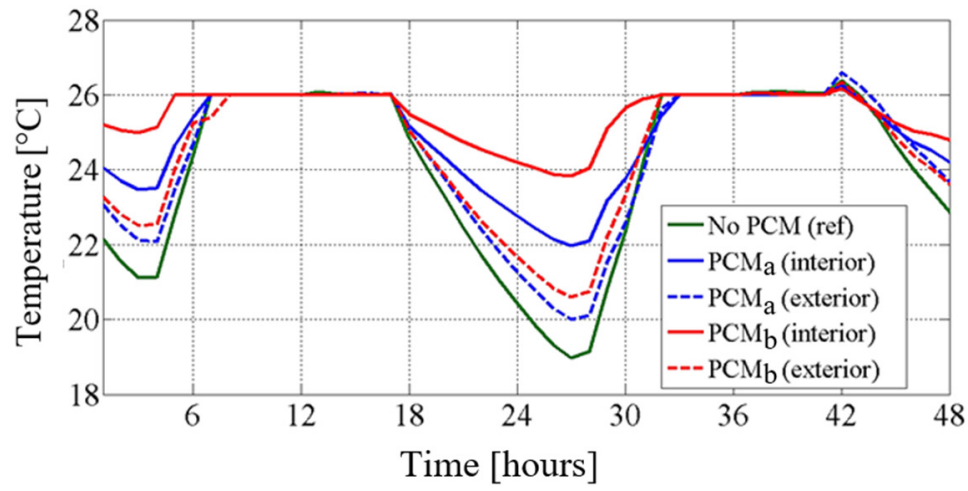

Figure 10. Indoor air temperatures for different building envelope configurations (office building in Denver, July $6^{\text {th }}$ and $7^{\mathrm{h}}$ )

During summer, because of the indoor air temperatures attenuation and delay (vs. those related to the reference case without PCM), the external PCM configuration allows $T_{\text {in }}$ to increase slowly with respect to other PCM cases. This is due to the capability to of the external PCM's to absorb and release solar radiation to the outdoor environment. As a result, in case of external PCM's, the morning activation of the HVAC system occurs later with respect to other cases (i.e. internal and reference). By comparing the thermal behaviour obtained by using $\mathrm{PCM}_{\mathrm{a}}$ and $\mathrm{PCM}_{\mathrm{b}}$ types, taking into account Figures 8-10, it is possible to observe that during winter the best PCM type from the energy point of view is the one with lowest melting/solidification peak temperatures, $\mathrm{PCM}_{\mathrm{a}}$. Contrarily, during summer, highest energy savings are obtained with the $\mathrm{PCM}_{b}$ type, as expected. It is worth noting that the overall energy performance depends on the weight of the heating and cooling energy requirements on the total (heating + cooling) ones.

The obtained overall yearly results are reported in Table 2 (office use) and in Table 3 (residential use). Here, the electricity demand of the chiller/heat pump of the traditional building (no PCM) and the achieved energy savings obtained by integrating PCM into the building envelope are reported for all the investigated weather zones and system layouts. For both the heating and cooling requirements, interesting electricity savings are obtained.

By analysing the overall energy results, reported in terms of electrical needs, it is possible to observe that the lowest energy needs are achieved by integrating PCM in the East and West walls and in the roof. Higher energy needs, still lower than those of the reference case, are calculated by considering PCM in the South and North walls. 
Nevertheless, it must be taken into account that for the first layout (i.e. East and West walls + roof) a higher amount of PCM is integrated into the building envelope with respect to the second layout (i.e. South and North walls). In particular, $2.1 \mathrm{~m}^{3}$ (first layout) and $1.2 \mathrm{~m}^{3}$ (second layout) of PCM are integrated into the building envelope. Therefore, although the calculated absolute energy savings are advantageous for the first layout, much higher energy savings potentials are obtained by taking into account the second one, as shown in Table 4. In this table, the percentage difference of total energy needs per cubic meters of PCM is reported for each investigated case. In Table 2 and Table 3 , the lowest energy needs, heating, cooling, and total, are underlined.

Table 2. Yearly heating, cooling and, total electrical energy results - office use.

\begin{tabular}{|c|c|c|c|c|c|c|c|c|c|c|c|c|c|c|c|c|}
\hline \multirow{4}{*}{ Weather zones } & \multirow{4}{*}{ Layout } & \multirow{2}{*}{\multicolumn{3}{|c|}{ No PCM (reference) }} & \multicolumn{6}{|c|}{$\mathrm{PCM}_{\mathrm{a}}$} & \multicolumn{6}{|c|}{$\mathrm{PCM}_{\mathrm{b}}$} \\
\hline & & & & & \multicolumn{3}{|c|}{$\begin{array}{l}\text { East and West walls + } \\
\text { roof }\end{array}$} & \multicolumn{3}{|c|}{ South and North walls } & \multicolumn{3}{|c|}{$\begin{array}{l}\text { East and West walls + } \\
\text { roof }\end{array}$} & \multicolumn{3}{|c|}{ South and North walls } \\
\hline & & Heat. & Cool. & Tot. & Heat. & Cool. & Tot. & Heat. & Cool. & Tot. & Heat. & Cool. & Tot. & Heat. & Cool. & Tot. \\
\hline & & \multicolumn{15}{|c|}{$\left[\mathrm{kWh} / \mathrm{m}^{2} \mathrm{y}\right]$} \\
\hline \multirow{2}{*}{ Denver } & Internal & \multirow{2}{*}{56.7} & \multirow{2}{*}{12.6} & \multirow{2}{*}{23.9} & 53.4 & 6.6 & 20.4 & 48.8 & 8.5 & 19.7 & 51.4 & 8.1 & 20.4 & 48.1 & 10.0 & 20.0 \\
\hline & External & & & & $\underline{44.0}$ & $\overline{9.4}$ & 18.4 & 44.8 & 11.4 & 19.5 & 44.6 & 9.4 & 18.6 & 45.2 & 11.5 & 19.7 \\
\hline \multirow{2}{*}{ Naples } & Internal & \multirow{2}{*}{18.3} & \multirow{2}{*}{20.5} & \multirow{2}{*}{14.3} & $\overline{14.2}$ & $\underline{16.6}$ & $\overline{11.4}$ & 13.6 & 17.9 & 11.7 & 14.1 & 19.2 & 12.4 & 13.5 & 19.8 & 12.4 \\
\hline & External & & & & 12.7 & $\overline{17.8}$ & 11.4 & 13.2 & 19.1 & 12.0 & 13.0 & 17.6 & 11.4 & 13.4 & 19.2 & 12.1 \\
\hline \multirow{2}{*}{ Jerusalem } & Internal & \multirow{2}{*}{16.0} & \multirow{2}{*}{21.5} & \multirow{2}{*}{13.9} & 10.9 & $\underline{16.5}$ & $\underline{10.3}$ & 10.5 & 18.2 & 10.8 & 10.8 & 19.3 & 11.3 & 10.4 & 20.5 & 11.7 \\
\hline & External & & & & $\underline{10.2}$ & $\overline{18.2}$ & $\overline{10.7}$ & 10.7 & 20.0 & 11.5 & 10.4 & $\underline{17.9}$ & $\underline{10.6}$ & 10.8 & 20.1 & 11.7 \\
\hline \multirow{2}{*}{ Athens } & Internal & \multirow{2}{*}{13.5} & \multirow{2}{*}{26.9} & \multirow{2}{*}{15.3} & $\underline{8.5}$ & 26.5 & 13.5 & 8.6 & 26.5 & 13.4 & 8.7 & 29.0 & 14.5 & 8.7 & 28.1 & 14.1 \\
\hline & External & & & & 8.6 & 24.8 & 12.8 & 9.0 & 25.8 & 13.3 & 8.8 & $\underline{24.6}$ & $\underline{12.8}$ & 9.1 & 25.8 & 13.4 \\
\hline \multirow{2}{*}{ Montreal } & Internal & \multirow{2}{*}{88.7} & \multirow{2}{*}{10.4} & \multirow{2}{*}{33.7} & 99.5 & $\underline{5.4}$ & 35.3 & 89.6 & 7.0 & 32.7 & 96.4 & 6.9 & 34.9 & 88.3 & 8.3 & 32.7 \\
\hline & External & & & & $\underline{77.9}$ & $\overline{8.2}$ & 29.2 & 78.2 & 9.2 & 29.8 & 78.2 & 8.2 & 29.4 & 78.5 & 9.3 & 29.9 \\
\hline \multirow{2}{*}{ Palermo } & Internal & \multirow{2}{*}{8.3} & & 12 & 2.0 & 21.8 & 9.4 & 2.8 & 22.3 & 9.8 & 2.1 & 24.2 & 10.4 & 2.7 & 24.0 & 10.5 \\
\hline & External & & 23.3 & 12.1 & $\overline{3.7}$ & 21.4 & 9.8 & 4.1 & 22.5 & 10.4 & 3.7 & 21.1 & 9.7 & 4.1 & 22.5 & 10.4 \\
\hline & Internal & 100 & 185 & 107 & 2.9 & 16.2 & 7.4 & 3.9 & 17.1 & 8.1 & 3.0 & $\overline{18.4}$ & $\overline{8.4}$ & 3.8 & 18.8 & 8.8 \\
\hline & External & 10.0 & & & 4.7 & 16.2 & 8.1 & 5.3 & 17.6 & 8.8 & 4.8 & 16.1 & 8.0 & 5.3 & 17.8 & 8.9 \\
\hline
\end{tabular}

Table 3. Yearly heating, cooling and, total electrical energy results - residential use

\begin{tabular}{|c|c|c|c|c|c|c|c|c|c|c|c|c|c|c|c|c|}
\hline \multirow{4}{*}{ Weather zones } & \multirow{4}{*}{ Layout } & \multirow{2}{*}{\multicolumn{3}{|c|}{$\begin{array}{l}\text { No PCM } \\
\text { (reference) }\end{array}$}} & \multicolumn{6}{|c|}{$\mathrm{PCM}_{\mathrm{a}}$} & \multicolumn{6}{|c|}{$\mathrm{PCM}_{\mathrm{b}}$} \\
\hline & & & & & \multicolumn{3}{|c|}{$\begin{array}{c}\text { East and West walls + } \\
\text { roof }\end{array}$} & \multicolumn{3}{|c|}{ South and North walls } & \multicolumn{3}{|c|}{$\begin{array}{l}\text { East and West walls + } \\
\text { roof }\end{array}$} & \multicolumn{3}{|c|}{ South and North walls } \\
\hline & & Heat. & Cool. & Tot. & Heat. & Cool. & Tot. & Heat. & Cool. & Tot. & Heat. & Cool. & Tot. & Heat. & Cool. & Tot. \\
\hline & & \multicolumn{15}{|c|}{$\left[\mathrm{kWh} / \mathrm{m}^{2} \mathrm{y}\right]$} \\
\hline \multirow{2}{*}{ Denver } & Internal & \multirow{2}{*}{56.3} & \multirow{2}{*}{15.8} & \multirow{2}{*}{25.1} & 56.8 & 9.7 & 22.8 & 56.7 & 11.5 & 23.5 & 56.4 & 11.0 & 23.2 & 56.4 & 13.1 & 24.0 \\
\hline & External & & & & $\underline{55.7}$ & $\underline{10.6}$ & $\underline{22.8}$ & 56.7 & 13.9 & 24.5 & 56.3 & 10.8 & 23.1 & 57.2 & 14.2 & 24.7 \\
\hline \multirow{2}{*}{ Naples } & Internal & \multirow{2}{*}{18.7} & \multirow{2}{*}{27.8} & \multirow{2}{*}{17.4} & $\overline{17.8}$ & $\overline{25.2}$ & $\overline{16.0}$ & 17.8 & 26.2 & 16.4 & 17.8 & 26.8 & 16.7 & 18.0 & 27.7 & 17.1 \\
\hline & External & & & & 18.0 & 23.7 & $\underline{15.5}$ & 18.5 & 25.9 & 16.5 & 18.3 & 23.7 & 15.6 & 18.6 & 26.1 & 16.7 \\
\hline \multirow{2}{*}{ Jerusalem } & Internal & \multirow{2}{*}{15.4} & \multirow{2}{*}{29.9} & \multirow{2}{*}{17.1} & 13.2 & 26.0 & 14.8 & 13.7 & 27.5 & 15.6 & 13.2 & 27.6 & 15.4 & 13.7 & 29.4 & 16.3 \\
\hline & External & & & & $\overline{14.1}$ & 24.5 & 14.5 & 14.7 & 27.9 & 16.1 & 14.3 & 24.3 & $\underline{14.5}$ & 14.9 & 28.2 & 16.2 \\
\hline \multirow{2}{*}{ Athens } & Internal & \multirow{2}{*}{12.7} & \multirow{2}{*}{36.5} & \multirow{2}{*}{18.8} & $\underline{10.8}$ & 37.1 & 18.4 & 11.2 & 37.4 & 18.7 & 10.9 & $\overline{38.1}$ & $\overline{18.9}$ & 11.3 & 38.1 & 19.0 \\
\hline & External & & & & $\overline{11.6}$ & 33.2 & $\underline{17.1}$ & 12.1 & 35.2 & 18.1 & 11.8 & $\underline{32.8}$ & 17.1 & 12.2 & 35.1 & 18.1 \\
\hline \multirow{2}{*}{ Montreal } & Internal & \multirow{2}{*}{$\underline{113.6}$} & \multirow{2}{*}{13.6} & \multirow{2}{*}{43.3} & 115.1 & $\underline{8.1}$ & 41.6 & 117.5 & 9.7 & 43.1 & 115.0 & 9.8 & 42.2 & 117.2 & 11.3 & 43.6 \\
\hline & External & & & & 117.5 & $\overline{9.7}$ & $\overline{43.1}$ & 118.9 & 11.6 & 44.3 & 117.8 & 10.1 & 43.3 & 119.1 & 11.8 & 44.4 \\
\hline Palermo & Internal & 6.7 & 325 & 152 & $\underline{3.5}$ & 31.9 & 13.9 & 4.5 & 32.6 & 14.5 & 3.6 & 32.9 & 14.3 & 4.4 & 33.3 & 14.8 \\
\hline & Internal & & & & 4.4 & 22.0 & 10.2 & 5.5 & 22.6 & 10.9 & 4.3 & 23.6 & 10.9 & 5.3 & 24.0 & 11.4 \\
\hline Almeria & External & 7.8 & 22.6 & 11.6 & 6.4 & 19.5 & 10.0 & 7.0 & 21.6 & 11.0 & $\overline{6.5}$ & $\underline{19.5}$ & 9.9 & 7.0 & 21.8 & 11.1 \\
\hline
\end{tabular}

In Table 4, the highest energy percentage difference (positive values mean energy savings) of the office building is underlined, whereas the italic style is used for the highest energy saving achieved by residential buildings. Some general considerations are summarized in the following. With the exception of Montreal (residential building use), where a continuous HVAC operation $(24 \mathrm{~h})$ due to the very cold winter weather is assumed, for all the investigated weather zones and building use, the use of PCM produces heating energy savings. In winter, the $\mathrm{PCM}_{\mathrm{a}}$ type shows the best energy performance if located in the external position, especially for the colder weather zones, whereas better performance is achieved by the $\mathrm{PCM}_{\mathrm{a}}$ located internally for warmer weather zones. In case of residential use, the internal position is preferable (stored heat is released inside the thermal zone in late evening or early night hours with the HVAC still running, improving energy savings and comfort). During summer, in case of temperate 
or Mediterranean weather zones, the best energy performance is obtained by the $\mathrm{PCM}_{\mathrm{b}}$ type, located in external position. Concerning the total energy needs, the energy saving percentage potentials per cubic meter of PCM range from $1.9 \% / \mathrm{m}^{3}$ in Montreal to $7.4 \% / \mathrm{m}^{3}$ in Jerusalem. For the office building use, the minimum energy saving potentials is achieved in Montreal, $9.8 \% / \mathrm{m}^{3}$, whereas the maximum is obtained in Jerusalem, $18.8 \% / \mathrm{m}^{3}$ (Table 4 ). Here, the highest energy potentials are observed by integrating PCM within the South and North walls. This layout is also the less expensive, due to the lower amount of PCM integrated within the building envelope.

Finally, it is worth noting that for all the investigated system configurations, although there are interesting energy savings, the operating economic savings are still too low to balance the current initial PCM cost to obtain acceptable paybacks.

Table 4. Percentage difference of total electrical energy per cubic meter of PCM

\begin{tabular}{|c|c|c|c|c|c|c|c|c|}
\hline & & & & \multicolumn{2}{|c|}{$\Delta E_{\mathrm{el}}\left[\% / \mathrm{m}^{3}\right]$} & & \multicolumn{2}{|c|}{$\Delta E_{\mathrm{el}}\left[\% / \mathrm{m}^{3}\right]$} \\
\hline & & & & $\begin{array}{c}\text { East and West walls + } \\
\text { roof }\end{array}$ & $\begin{array}{c}\text { South and } \\
\text { North walls }\end{array}$ & & $\begin{array}{l}\text { East and West walls + } \\
\text { roof }\end{array}$ & $\begin{array}{l}\text { South and } \\
\text { North walls }\end{array}$ \\
\hline \multirow{4}{*}{$\mathrm{PCM}_{\mathrm{a}}$} & \multirow{2}{*}{ Office } & Internal & & 6.9 & 14.7 & \multirow{8}{*}{$\frac{\frac{\tilde{g}}{\tilde{z}}}{\frac{z}{z}}$} & 9.7 & $\underline{15.3}$ \\
\hline & & External & & 11.0 & $\underline{15.5}$ & & 9.8 & $\overline{13.2}$ \\
\hline & \multirow{2}{*}{ Residential } & Internal & & 4.3 & 5.4 & & 3.7 & 5.4 \\
\hline & & External & $\grave{D}$ & 4.4 & 2.1 & & 5.1 & 4.0 \\
\hline \multirow{4}{*}{$\mathrm{PCM}_{\mathrm{b}}$} & \multirow{2}{*}{ Office } & Internal & อี & 7.1 & 13.5 & & 6.5 & 11.0 \\
\hline & & External & & 10.6 & 14.8 & & 9.8 & 12.7 \\
\hline & \multirow{2}{*}{ Residential } & Internal & & 3.6 & 3.5 & & 1.9 & 1.4 \\
\hline & & External & & 3.8 & 1.2 & & 4.9 & 3.4 \\
\hline \multirow{4}{*}{$\mathrm{PCM}_{\mathrm{a}}$} & \multirow{2}{*}{ Office } & Internal & & 12.5 & $\underline{18.8}$ & \multirow{8}{*}{$\frac{\mathscr{a}}{\frac{D}{E}}$} & 5.7 & 10.0 \\
\hline & & External & & 11.1 & $\overline{14.2}$ & & 7.8 & $\underline{10.6}$ \\
\hline & \multirow{2}{*}{ Residential } & Internal & $\Xi$ & 6.4 & 7.4 & & 1.0 & 0.6 \\
\hline & & External & $\frac{\bar{\nu}}{\pi}$ & 7.2 & 5.1 & & 4.3 & 3.3 \\
\hline \multirow{4}{*}{$\mathrm{PCM}_{\mathrm{b}}$} & \multirow{2}{*}{ Office } & Internal & $\sum_{0}^{2}$ & 8.8 & 13.4 & & 2.4 & 6.1 \\
\hline & & External & & 11.3 & 13.5 & & 7.8 & 10.4 \\
\hline & \multirow{2}{*}{ Residential } & Internal & & 4.6 & 3.7 & & -0.2 & -0.8 \\
\hline & & External & & 7.2 & 4.2 & & 4.4 & 3.1 \\
\hline \multirow{4}{*}{$\mathrm{PCM}_{\mathrm{a}}$} & \multirow{2}{*}{ Office } & Internal & & -2.3 & 2.6 & \multirow{8}{*}{ 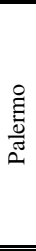 } & 10.6 & 15.7 \\
\hline & & External & & 6.3 & $\underline{9.8}$ & & 9.2 & 11.9 \\
\hline & \multirow{2}{*}{ Residential } & Internal & $\bar{\pi}$ & 1.9 & 0.5 & & 4.0 & 3.8 \\
\hline & & External & $\stackrel{\Xi}{\Xi}$ & 0.3 & -1.8 & & 5.5 & 3.8 \\
\hline \multirow{4}{*}{$\mathrm{PCM}_{\mathrm{b}}$} & \multirow{2}{*}{ Office } & Internal & ฮี & -1.7 & 2.5 & & 6.7 & 11.0 \\
\hline & & External & & 6.2 & 9.5 & & 9.5 & 11.9 \\
\hline & \multirow{2}{*}{ Residential } & Internal & & 1.2 & -0.5 & & 2.7 & 2.3 \\
\hline & & External & & 0.0 & -2.2 & & 5.8 & 3.9 \\
\hline \multirow{4}{*}{$\mathrm{PCM}_{\mathrm{a}}$} & \multirow{2}{*}{ Office } & Internal & & 1414.6 & 20.2 & & & \\
\hline & & External & & 11.8 & $\underline{14.8}$ & & & \\
\hline & \multirow{2}{*}{ Residential } & Internal & & 5.7 & 5.5 & & & \\
\hline & & External & $\overrightarrow{\frac{\pi}{0}}$ & 6.9 & 4.7 & & & \\
\hline \multirow{4}{*}{$\mathrm{PCM}_{\mathrm{b}}$} & \multirow{2}{*}{ Office } & Internal & $\frac{\mathrm{g}}{<}$ & 10.5 & 15.1 & & & \\
\hline & & External & & 11.9 & 14.3 & & & \\
\hline & & Internal & & 3.2 & 2.0 & & & \\
\hline & Residential & External & & 6.7 & 4.0 & & & \\
\hline
\end{tabular}

\section{CONCLUSIONS}

This paper focuses on a comprehensive analysis of the effectiveness of the integration of PCM's in the building envelope. To this aim, a mathematical model for the energy performance of buildings (DETECt 2.3) has been suitably modified in order to model and simulate PCM wallboards. For analysing different PCM's, data obtained by a previously carried out experimental characterization are taken into account.

A case studies analysis is carried out by simulating residential and non-residential uses concerning a building located in seven weather zones. Different scenarios (e.g. different PCM configurations and types, variable weather conditions, etc.) are analysed in order to show and discuss some crucial effects due to the use of PCM's in the building envelope on its energy requirements and comfort level of occupants.

The main finding regards the position of the PCM within the building envelope (e.g. integrated interior or exterior envelope layers of perimeter walls and roof) aiming at effectively reducing the building energy demand. In particular, the optimal position of 
PCM panels highly depends on the building use (i.e. internal gains) and weather conditions (i.e. external solicitation). Therefore, to obtain representative results, its use should be studied with care on a yearly basis, since a well behaving material during summer could be a poor choice in winter. To this aim, the use of dynamic simulations carried out on the yearly, is crucial.

Finally, the developed tool provides interesting design criteria for the development and adoption of building integrated PCM's. Further analyses will be performed (also focusing on the system optimization by taking into account several objective functions) with the aim to comprehensively investigate the relationships among PCM properties (e.g. peak melting temperature, melting range, etc.) and overall building energy consumptions.

\section{NOMENCLATURE}

$\begin{array}{clc}c & \text { specific heat } & {[\mathrm{J} / \mathrm{KgK}] / \mathrm{range} \text { of phase change }} \\ C & \text { thermal capacitance } & {[\mathrm{J} / \mathrm{K}]} \\ \dot{Q} & \text { thermal load } & {[\mathrm{W}]} \\ M & \text { mass } & {[\mathrm{kg}]} \\ N & \text { building component thermal node } & {[-]} \\ R & \text { thermal resistance } & {[\mathrm{K} / \mathrm{W}]} \\ T & \text { temperature } & {[\mathrm{K}]} \\ t & \text { time } & {[\mathrm{h}]}\end{array}$

\section{Subscripts/Superscripts}

a maximum increment of phase change material specific heat due to latent heat

ac heating, ventilation and air conditioning system

b average phase change temperature for melting and solidification

conv convective

eq equivalent

g gain

HC heating/cooling

in indoor air

$m \quad$ generic $m$-th building element

$n \quad$ generic building element thermal node

out outdoor air

$\mathrm{r}$ radiant

ref reference

$\mathrm{v} \quad$ ventilation

\section{Abbreviations}

CDD Cooling Degree Days

COP Coefficient of Performance

HDD Heating Degree Days

HVAC Heating, Ventilation and

Air Conditioning

PCM Phase Change Material

PPD Percentage of Person Dissatisfied

RC Resistive/Capacitive

SHGC Solar Heat Gain Coefficient 


\section{REFERENCES}

1. International Energy Agency (IEA), Energy Climate and Change, World Energy Outlook Special Report, 2016.

2. Buonomano, A., Forzano, C., Kalogirou, S. A. and Palombo, A., Building-façade Integrated Solar Thermal Collectors: Energy-economic Performance and Indoor Comfort Simulation Model of a Water Based Prototype for Heating, Cooling, and DHW Production (in press), Renewable Energy, 2018, https://doi.org/10.1016/j.renene.2018.01.059

3. Athienitis, A. K., Barone, G., Buonomano, A. and Palombo, A., Assessing Active and Passive Effects of Façade Building Integrated Photovoltaics/thermal Systems: Dynamic Modelling and Simulation, Applied Energy, Vol. 209, pp 355-382, 2018, https://doi.org/10.1016/j.apenergy.2017.09.039

4. Akeiber, H., Nejat, P., Majid, M. Z. A., Wahid, M. A., Jomehzadeh, F., Zeynali Famileh, I., Calautit, J. K., Hughes, B. R. and Zaki, S. A., A Review on Phase Change Material (PCM) for Sustainable Passive Cooling in Building Envelopes, Renewable and Sustainable Energy Reviews, Vol. 60, pp 1470-1497, 2016, https://doi.org/10.1016/j.rser.2016.03.036

5. Zhang, Y., Zhou, G., Lin, K., Zhang, Q. and Di, H., Application of Latent Heat Thermal Energy Storage in Buildings: State-of-the-art and Outlook, Building and Environment, Vol. 42, No. 6, pp 2197-2209, 2007, https://doi.org/10.1016/j.buildenv.2006.07.023

6. Boussaba, L., Foufa, A., Makhlouf, S., Lefebvre, G. and Royon, L., Elaboration and Properties of a Composite Bio-based PCM for an Application in Building Envelopes, Construction and Building Materials, Vol. 185, pp 156-165, 2018, https://doi.org/10.1016/j.conbuildmat.2018.07.098

7. Kheradmand, M., Castro-Gomes, J., Azenha, M., Silva, P. D., de Aguiar, J. L. B. and Zoorob, S. E., Assessing the Feasibility of Impregnating Phase Change Materials in Lightweight Aggregate for Development of Thermal Energy Storage Systems, Construction and Building Materials, Vol. 89, pp 48-59, 2015, https://doi.org/10.1016/j.conbuildmat.2015.04.031

8. Ling, T.-C. and Poon, C.-S., Use of Phase Change Materials for Thermal Energy Storage in Concrete: An Overview, Construction and Building Materials, Vol. 46, pp 55-62, 2013, https://doi.org/10.1016/j.conbuildmat.2013.04.031

9. Lei, J., Yang, J. and Yang, E.-H., Energy Performance of Building Envelopes Integrated with Phase Change Materials for Cooling Load Reduction in Tropical Singapore, Applied Energy, Vol. 162, pp 207-217, 2016, https://doi.org/10.1016/j.apenergy.2015.10.031

10. Cabeza, L. F., Castell, A., Barreneche, C., de Gracia, A. and Fernández, A. I., Materials Used as PCM in Thermal Energy Storage in Buildings: A Review, Renewable and Sustainable Energy Reviews, Vol. 15, No. 3, pp 1675-1695, 2011, https://doi.org/10.1016/j.rser.2010.11.018

11. Souayfane, F., Fardoun, F. and Biwole, P.-H., Phase Change Materials (PCM) for Cooling Applications in Buildings: A Review, Energy and Buildings, Vol. 129, pp 396-431, 2016, https://doi.org/10.1016/j.enbuild.2016.04.006

12. Kasaeian, A., Bahrami, L., Pourfayaz, F., Khodabandeh, E. and Yan, W.-M., Experimental Studies on the Applications of PCM's and Nano-PCM's in Buildings: A Critical Review, Energy and Buildings, Vol. 154, pp 96-112, 2017, https://doi.org/10.1016/j.enbuild.2017.08.037

13. Fabiani, C. and Pisello, A. L., Coupling the Transient Plane Source Method with a Dynamically Controlled Environment to Study PCM-doped Building Materials, Energy and Buildings, Vol. 180, pp 122-134, 2018, https://doi.org/10.1016/j.enbuild.2018.09.008 
14. Chan, A. L. S., Energy and Environmental Performance of Building Façades Integrated with Phase Change Material in Subtropical Hong Kong, Energy and Buildings, Vol. 43, No. 10, pp 2947-2955, 2011, https://doi.org/10.1016/j.enbuild.2011.07.021

15. Ascione, F., Bianco, N., De Masi, R. F., de' Rossi, F. and Vanoli, G. P., Energy Refurbishment of Existing Buildings Through the Use of Phase Change Materials: Energy Savings and Indoor Comfort in the Cooling Season, Applied Energy, Vol. 113, pp 990-1007, 2014, https://doi.org/10.1016/j.apenergy.2013.08.045

16. Stritih, U., Tyagi, V. V., Stropnik, R., Paksoy, H., Haghighat, F. and Joybari, M. M., Integration of Passive PCM Technologies for Net-zero Energy Buildings, Sustainable Cities and Society, Vol. 41, pp 286-295, 2018, https://doi.org/10.1016/j.scs.2018.04.036

17. Iten, M., Liu, S. and Shukla, A., A Review on the Air-PCM-TES Application for Free Cooling and Heating in the Buildings, Renewable and Sustainable Energy Reviews, Vol. 61, pp 175-186, 2016, https://doi.org/10.1016/j.rser.2016.03.007

18. Xie, J., Wang, W., Liu, J. and Pan, S., Thermal Performance Analysis of PCM Wallboards for Building Application Based on Numerical Simulation, Solar Energy, Vol. 162, pp 533-540, 2018, https://doi.org/10.1016/j.solener.2018.01.069

19. Buonomano, A., De Luca, G., Montanaro, U. and Palombo, A., Innovative Technologies for NZEBs: An Energy and Economic Analysis Tool and a Case Study of a Non-residential Building in Mediterranean Climate, Energy and Buildings, Vol. 121, pp 318-343, 2016, http://dx.doi.org/10.1016/j.enbuild.2015.08.037

20. Buonomano, A., De Luca, G., Montanaro, U. and Palombo, A., Innovative Technologies for NZEBs: An Energy and Economic Analysis Tool and a Case Study of a Non-residential Building for the Mediterranean Climate, Energy and Buildings, Vol. 121, pp 318-343, 2016, https://doi.org/10.1016/j.enbuild.2015.08.037

21. Buonomano, A., Montanaro, U., Palombo, A. and Santini, S., Dynamic Building Energy Performance Analysis: A New Adaptive Control Strategy for Stringent Thermohygrometric Indoor Air Requirements, Applied Energy, Vol. 163, pp 361-386, 2016, https://doi.org/10.1016/j.apenergy.2015.10.182

22. Buonomano, A., Calise, F., Palombo, A. and Vicidomini, M., BIPVT Systems for Residential Applications: An Energy and Economic Analysis for European Climates, Applied Energy, Vol. 184, Suppl. C, pp 1411-1431, 2016, https://doi.org/10.1016/j.apenergy.2016.02.145

23. Judkoff, R. and Neymark, J., International Energy Agency Building Energy Simulation Test (BESTEST) and Diagnostic Method, Technical Report, NREL/TP472-6231, Washington D. C., USA, 2005.

24. Buonomano, A. and Palombo, A., Building Energy Performance Analysis by an Inhouse Developed Dynamic Simulation Code: An Investigation for Different Case Studies, Applied Energy, Vol. 113, pp 788-807, 2014, https://doi.org/10.1016/j.apenergy.2013.08.004

25. Buonomano, A. and Palombo, A., Nzebs Design and Simulation: A New Tool for Dynamic Energy performance Analyses, Proceedings of the $27^{\text {th }}$ International Conference on Efficiency, Cost, Optimization, Simulation and Environmental Impact of Energy Systems (ECOS), Turku, Finland, 2014.

26. Barone, G., Buonomano, A., Forzano, C. and Palombo, A., Experimental Validation of a Dynamic Building Energy Simulation Tool and Case Study Analysis on Lowemissivity and High-reflective Coatings, Proceedings of the $13^{\text {th }}$ Conference on Sustainable Development of Energy, Water and Environment Systems (SDEWES), Palermo, Italy, 2018.

27. Tsilingiris, P. T., Parametric Space Distribution Effects of Wall Heat Capacity and Thermal Resistance on the Dynamic Thermal Behavior of Walls and Structures, 
Energy and Buildings, Vol. 38, No. 10, pp 1200-1211, 2006, https://doi.org/10.1016/j.enbuild.2006.02.007

28. MATlab, https://www.mathworks.com/, [Accessed: 25-November-2018]

29. Buonomano, A., Code-to-Code Validation and Application of a Dynamic Simulation Tool for the Building Energy Performance Analysis, Energies, Vol. 9, No. 4, p 301, 2016, https://doi.org/10.3390/en9040301

30. Tittelein, P., Gibout, S., Franquet, E., Johannes, K., Zalewski, L., Kuznik, F., Dumas, J.-P., Lassue, S., Bédécarrats, J.-P. and David, D., Simulation of the Thermal and Energy Behaviour of a Composite Material Containing Encapsulated-PCM: Influence of the Thermodynamical Modelling, Applied Energy, Vol. 140, pp 269-274, 2015, https://doi.org/10.1016/j.apenergy.2014.11.055

31. Soares, N., Costa, J. J., Gaspar, A. R. and Santos, P., Review of Passive PCM Latent Heat Thermal Energy Storage Systems Towards Buildings' Energy Efficiency, Energy and Buildings, Vol. 59, pp 82-103, 2013, https://doi.org/10.1016/j.enbuild.2012.12.042

32. Kuznik, F., Virgone, J. and Johannes, K., Development and Validation of a New TRNSYS Type for the Simulation of External Building Walls Containing PCM, Energy and Buildings, Vol. 42, No. 7, pp 1004-1009, 2010, https://doi.org/10.1016/j.enbuild.2010.01.012

33. Goia, F., Chaudhary, G. and Fantucci, S., Modelling and Experimental Validation of an Algorithm for Simulation of Hysteresis Effects in Phase Change Materials for Building Components, Energy and Buildings, Vol. 174, pp 54-67, 2018, https://doi.org/10.1016/j.enbuild.2018.06.001

34. ISO 7730:2006, Ergonomics of Thermal Environment - Analytical Determination and Interpretation of Thermal Comfort Using Calculation of the PMV and PPD Indices and Local Thermal Comfort Criteria, p 52, 2005.

35. d'Ambrosio Alfano, F. R., Ianniello, E. and Palella, B. I., PMV-PPD and Acceptability in Naturally Ventilated Schools, Building and Environment, Vol. 67, pp 129-137, 2013, https://doi.org/10.1016/j.buildenv.2013.05.013

36. Kuznik, F., Virgone, J. and Noel, J., Optimization of a Phase Change Material Wallboard for Building Use, Applied Thermal Engineering, Vol. 28, No. 11-12, pp 1291-1298, 2008, https://doi.org/10.1016/j.applthermaleng.2007.10.012 